International Journal of Advanced Technology in Mechanical, Mechatronics and Materials

(IJATEC)

Vol. 01, No. 1 (2020) 26-31

(C) Institute for Research on Innovation and Industrial System (IRIS)

\title{
New Method of Fabrication of Fe80Cr20 Alloy: Effect of its Technique on Crystallite Size and Thermal Stability
}

\author{
Dafit Feriyanto*a, Supaat Zakariab \\ ${ }^{a}$ Faculty of Engineering, Universitas Mercu Buana, Jakarta, Indonesia \\ ${ }^{b}$ Department of Mechanical Engineering, Politeknik Ungku Omar, Malaysia
}

\begin{abstract}
This paper focuses on the effect of the new method on the crystallite size and thermal stability of Fe80Cr20 alloy powder. Generally, the ball milling sample and ultrasonic technique sample have dissatisfaction result when applied at high temperature. In addition, the combination of both techniques not yet carried out. Therefore, this study aims to investigate an appropriate technique to produce smallest crystallite size in order to improve the thermal stability. The new method of mechanical alloying (mill) and ultrasonic technique (UT) were applied in order to reduce the crystallite size and improve thermal stability. The new method is called as combination treatment. This condition allows the enhancement of thermal stability of Fe80Cr20 alloy powder. In this study, mechanical alloying process was carried out by milling time of 60 hours. Then, the ultrasonic technique was performed at frequency of $35 \mathrm{kHz}$ at 3, 3.5, 4, 4.5, and 5 hours. From XRD analysis, it was found that the broader peaks indicated the smaller crystallite size. It shows that the combination treatment (milled and UT) reduce the crystallite size up to $2.171 \mathrm{~nm}$ when mechanically alloyed for 60 hours (milled $60 \mathrm{~h}$ ) and followed by ultrasonic treatment for 4.5 hours (UT $4.5 \mathrm{~h}$ ). Smallest crystallite size enhances the thermal stability up to $12.7 \mathrm{mg}$ which shown by TGA analysis during $11000 \mathrm{C}$ temperature operation. The combination treatment is method which is effective to fabricate Fe80Cr20 alloy powder.
\end{abstract}

Keywords: crystallite size; thermal stability; mechanical alloying; ultrasonic technique and interconnect

DOI: $10.37869 /$ ijatec.v1i1.11

Received 6 March 2020; Accepted 20 March 2020; Available online 30 March 2020

(C) 2020 IRIS Publisher. All rights reserved.

\section{Introduction}

The iron-chromium system has been used in long time as the basis by many engineering alloys for high-strength and corrosion-resistant applications, such as for fuel cell interconnect. Chromium acts as the $\alpha$-phase stabilizer when added into iron because chromium has the same Body Centre Cubic (BCC) crystal structure as $\alpha$-iron [1,2]. Many aspects of the properties and structure of Fe-Cr alloy powder required for more detail investigation. The oxidation of two commercial $\mathrm{Fe}-\mathrm{Cr}$ alloys which containing 16 and $22 \% \mathrm{Cr}$ in a wet methane atmosphere at $800{ }^{\circ} \mathrm{C}(1073 \mathrm{~K})$ have been studied [2]. The result indicated that at a higher chromium-containing alloys would have a slightly lower oxidation rate in that environment [2]. According to [3] the crystallite size of metallic material is decreased with the increasing of thermal stability during temperature operation of $650{ }^{\circ} \mathrm{C}$. Developing nanocrystallite metallic interconnect also studied by [4], they found that it was operated at temperature of $900^{\circ} \mathrm{C}$ which is give the effect that the higher thermal stability at smaller crystallite size up to $11 \mathrm{~nm}$. Higher thermal stability shown by smaller mass gain during temperature operation. Other study of $\mathrm{Fe}_{80} \mathrm{Cr}_{20}$ alloy powder investigated that the effect of the various sintering process and

*Corresponding author: dafit.feriyanto@mercubuana.ac.id ISSN: 2720-9008 
Lanthanum (La) implantation on the crystallite size [5, 6] and the results show that the growth rate of La implanted sample smaller than without La implanted during sintering process. Smaller crystallite size shows the smaller growth rate after sintering process. Intermetallic $\mathrm{Fe}_{80} \mathrm{Cr}_{20}$ developed by using mechanical alloying with milling time of 40 hours and 60 hours, prior to implanted by using Lanthanum (La), it is consolidated at temperature of $1273 \mathrm{~K}$ and pressure of 25 $\mathrm{MPa}$ [7]. FeCrAl is treated using ultrasonic technique prior to nickel electroplating which have been studied $[8,9]$ and they found that the ultrasonic technique effective to break the agglomerates or to improve homogeneity, improve surface morphology of the FeCrAl alloys. Some previous research above shows that the crystallite size of $\mathrm{Fe}_{80} \mathrm{Cr}_{20}$ alloy, clear correlation with temperature operation. Ball milling and ultrasonic technique is shown inconvenience results in growth rate of crystallite size at high temperature operation [3-11]. Therefore, this study will combine between ball milling and ultrasonic technique. The objective of this research is to evaluate the effect of that process on the diffraction peaks, crystallite size, strain, and thermal stability of $\mathrm{Fe}_{80} \mathrm{Cr}_{20}$ alloy powder.

\section{Research Methodology}

Raw materials consist of iron and chromium powders. The powder was mixed at $80 \mathrm{wt} \% \mathrm{Fe}$ and 20 $\mathrm{wt} \% \mathrm{Cr}$ compositions. In this research the synthesis was milling combined with ultrasonic treatment. The $\mathrm{Fe}_{80} \mathrm{Cr}_{20}$ alloy powder were mixed and sealed in a $250 \mathrm{ml}$ grinding jar with the ratio of the ball and the powder mass at 13:1 [12]. Hardened steel balls with varies diameters: 1 ball of $10 \mathrm{~mm}, 2$ balls of $15 \mathrm{~mm}, 5$ balls of $20 \mathrm{~mm}, 8$ balls of $27 \mathrm{~mm}$ is used in ball milling process. According to Hendi, (2011), the smallest crystallite size was obtained using milling time of $60 \mathrm{~h}$. Therefore, this research ball milling process was carried out at fixed milling time of 60 hours. Refine the surface morphology and more homogeneity was introduced using ultrasonic technique. The fixed frequency of ultrasonic machine is $35 \mathrm{kHz}$. The ultrasonic process was conducted at varies ultrasonic times of $3 \mathrm{~h}, 3.5 \mathrm{~h}, 4 \mathrm{~h}$, $4.5 \mathrm{~h}$ and $5 \mathrm{~h}$ for each sample. Characterizations phase using X-Ray Diffraction (XRD) and thermal analysis using Thermo Gravimetric Analysis (TGA). Crystallite size is determined using WilliamsonHall method as shown in (1) $[13,14]$.

$$
\partial(2 \theta) \operatorname{Cos} \theta=\frac{0.9 \lambda}{D_{W H}}+4 \varepsilon \operatorname{Sin}
$$

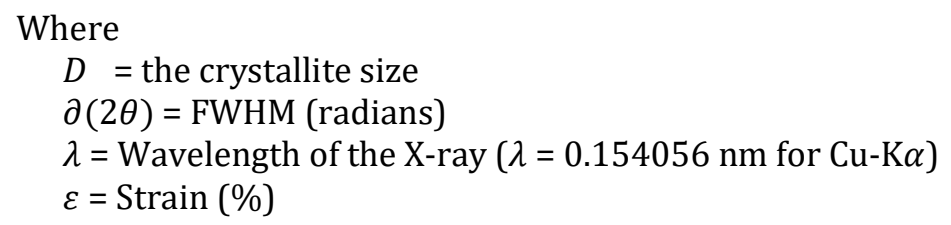

\section{Results and Discussions}

\subsection{XRD peaks and crystallite size properties}

Comparison of XRD pattern of the treated samples (UT samples, milled $60 \mathrm{~h}$ sample and combination treatment (milled and UT samples)) and untreated samples (raw material) is shown in Figure 1. Generally, the combination treatment samples show broader peak than raw material, UT samples and milled $60 \mathrm{~h}$ sample. Broader peaks are indicated that the smaller crystallite size of Fe80Cr20 alloy powder. This broadening is due to overlapping peaks in the iron and chromium. It is probably caused by the similarity of lattice parameter. The peaks are located at the reflection angle of 440, 650 and 820 which can be assigned to the peaks from the (110), (200) and (211) planes, respectively. 


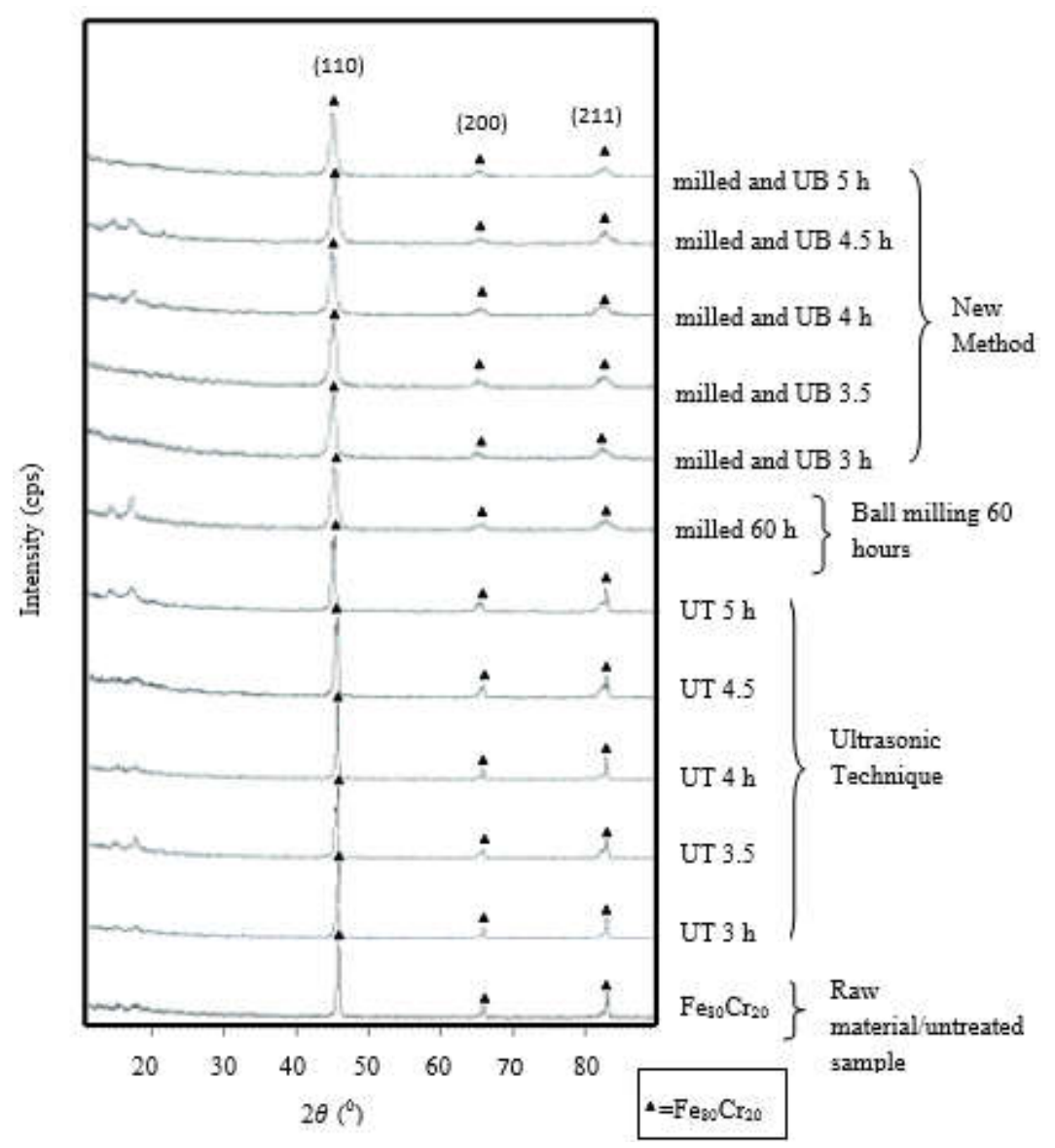

Figure 1. XRD pattern and crystal structure of the treated and untreated samples

\subsection{Crystallite size and strain analysis}

Crystallite size and strain is determined using Williamson-Hall method. The crystallite size and strain of the treated and untreated samples are shown in Figure 2.

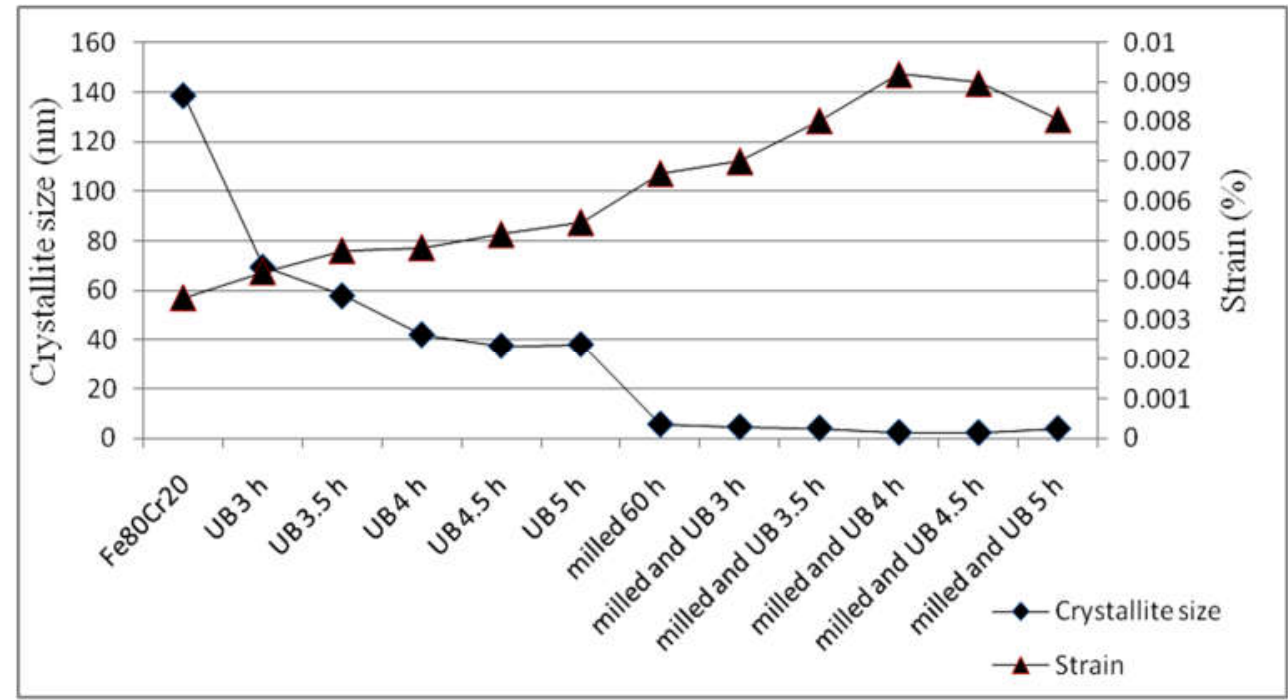

Figure 2. Crystallite size vs strain of research sample

The combination treatment has a significant effect to reduce the crystallite size. These phenomena are due to the $\mathrm{Fe}_{80} \mathrm{Cr}_{20}$ alloy powder and the crystallite size is smaller than $20 \mathrm{~nm}$, the total volume fraction of inter-crystalline region become significant. Therefore, the full dense material in the nano- 
crystalline material is developed. Strain of designation sample are relatively increase up to $62 \%$ from $\mathrm{Fe}_{80} \mathrm{Cr}_{20}$ sample to the combination (milled and UT) samples. Increasing sample strain means the deformation in term of relative displacement of particle in the body has increased. Deformation during ball milling and ultrasonic process formed a stress field because temperature is changed during the process. A continuous and discontinuous of crystallite size and material strain are included in Error! Reference source not found.. Crystallite size and strain on raw material until combination treatment (milled and UT $4.5 \mathrm{~h}$ ) samples are located in deformation elastic of material (continuous condition). Meanwhile, the deformation plastic of the material is located at milled and UT $5 \mathrm{~h}$ (discontinuous condition). That phenomenon also showed by $[4,15,16]$ that the temperature operation gives a great influence on the crystallite size which is shown by continuous and discontinuous/elastic and plastic area of the samples. Higher temperature is effect to the higher growth rate at same crystallite size and smaller crystallite size is effect to the smaller growth rate at the same temperature operation.

\subsection{Thermal stability analysis}

Thermal stability of material was analyzed using Thermo Gravimetric Analysis (TGA). Thermal stability is introduced by mass changes of the samples in high temperature operation. Mass change is obtained directly from TGA machine after the process complete. If the low mass changes is observed, it means that the material have a good thermal stability. Lower mass gain is shown in ball milling 60 hours and combination treatment samples. For more clearly understand of TGA curve as shown by Figure 1.

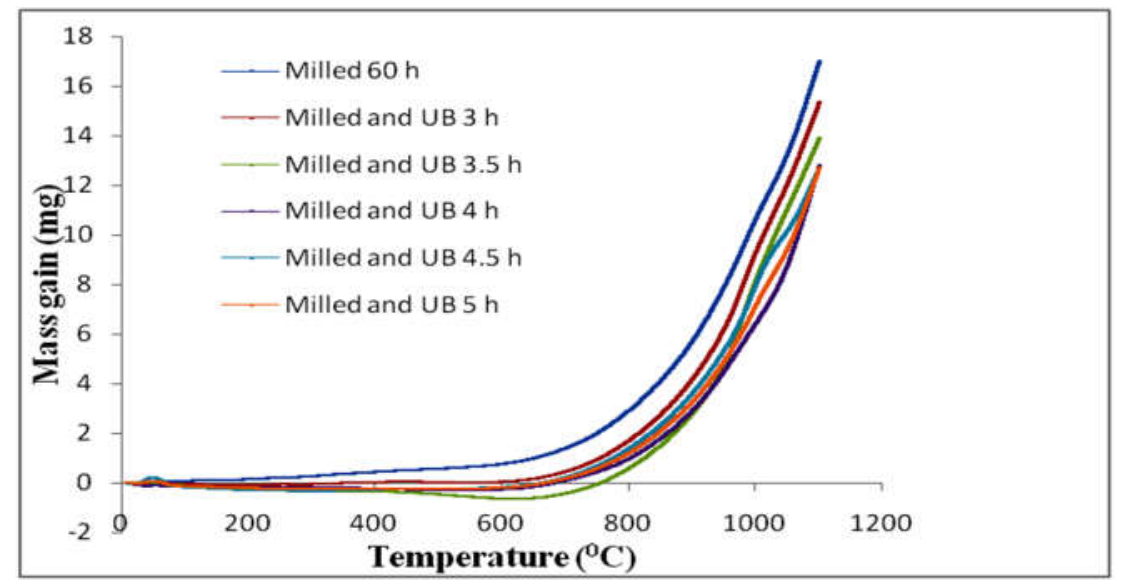

Figure 1. Mass gain of milled 60 hours and combination treatment samples

Influence of the crystallite size on the mass gain has been investigated. Therefore, the graphic of the crystallite size and mass gain in treated as well as untreated sample is shown in Figure 2.

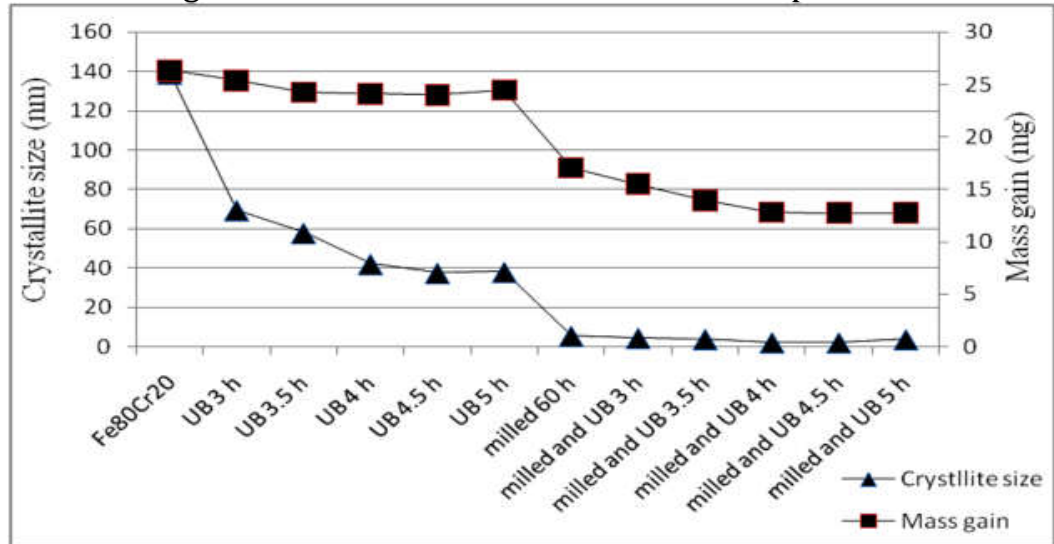

Figure 2. Mass gain vs crystallite size of the treated and untreated samples 
Reduction of the crystallite size of the sample designation has expected give effect to mass gain. Although on higher temperature operation, milled $60 \mathrm{~h}$ sample and combination treatment sample have smaller mass gain than raw material and UT samples. It is caused by reducing crystallite size after each process. Therefore, decreasing crystallite size will decrease the mass gain of the samples designation of $2.71 \mathrm{~nm}$ and $12.7 \mathrm{mg}$, respectively.

Crystallite size is decreased by mass gain which has decreased. It is relevant with the previous research that growth rate of crystallite size after consolidation process by using hot pressing was observed [3-6, 9]. Growth rate was increased at the larger crystallite size.

\section{Conclusions}

From XRD analysis allowed to precise determination of the crystal structure is (110), (200) and (211), plane crystal structure is Body Centered Cubic (BCC) and the sharper peaks show the smaller crystallite size. Outline/reverse correlation of the crystallite size and strain of the samples and in line correlation of the crystallite size and mass gain. The influence of the crystallite size on the thermal stability of the metallic interconnect from literature may result from differences in the method, composition and temperature operation. It was found that this result obtained by new method are consistent.

\section{References}

[1] Benjamin CC. Georgia Institute of Technology Atlanta, 2004; Georgia, Phd thesis.

[2] Smith WF. Structure and Properties of Engineering Alloys., 2nd ed., New York, McGraw-Hill; 1993.

[3] Angel Ortiz L., Osborn W., Markmaitree T., Leon Shaw L. Stability of Lithium Hydride in Argon and Air. Journal of Alloys and Compounds, 2008;454:297-305.

[4] Daengsakul S., Thomas C., Mongkolkachit C., Maensiri S. Effects of crystallite size on magnetic properties of thermal-hydro decomposition prepared La1-xSrxMnO3 nanocrystalline powders Solid State Sciences, 2012;14:1306-1314.

[5] Hadi Pranoto, Dafit Feriyanto, Supaat Zakaria. Performance and Exhaust Gas Temperature Investigation of Ceramic, Metallic and FeCrAl Catalytic Converter In Gasoline Engine. Sinergi, 2019;23(1):11-16

[6] Hadi Pranoto, Nurato Nurato, Dafit Feriyanto. Coating Thickness Analysis of Deposited FeCrAl Substrate By $\gamma$-AL2O3 Through NiO-Electroplating. Sinergi, 2018;22(3):177-184.

[7] Sebayang D., Hendi Saryanto, Pudji Untoro, Deni S. Khaerudini: Effect of depth implantation of lanthanum on the oxidation of Fe80Cr20 based alloys. World Congress on Engineering (WCE), London, UK 2010.

[8] Dafit Feriyanto, M. I. Idris, Darwin Sebayang. The Effect of Ultrasonic Treatment on The Oxidation Resistance and Microstructure of Fe80Cr20 Alloy Powder at High Temperature Oxidation Process. Advanced Materials Research, 2015;1087:126-130.

[9] Dafit Feriyanto, M. I. Idris, Darwin Sebayang. Effect of $\mathrm{Cr}$ to Fe on the Solid Solubility, Lattice Parameter and Strain of Fe80Cr20Alloy Powder. Applied Mechanics and Materials, 2014;660:280-284.

[10] Marwene O., Sobhi H., Mohamed B., Herbet B.S., Ieda MGS., Mohamed O. Spin-glass-like behaviour in ball milled Fe30Cr70 alloy studied by ac magnetic Susceptibility. Journal of Alloys and Compounds, 2013;5701:79-84.

[11] Okada K., Nagashima T., Kameshima Y., and Yasumori A. Effect of Crystallite Size on the Thermal Phase Change and Porous Properties of Boehmite Journal of Colloid and Interface Science, 2002;248:111-115.

[12] Fnidiki A., Lemoine C., Teillet J. Properties of mechanically alloyed Fe 100-x Crx powder mixtures: Mossbauer study Physica, 2005;357:319-325.

[13] Mittemeijer, E.J. \& U. Welzel: Z. The "State of The Art" of the diffraction analysis of crystallite size and lattice strain. Kristallogr, 2008;233:552-560. 
[14] Ungar T., Gubicza J., Ribaarik G. \& Borbealy A.: Aqueous chemical growth of alpha-Fe203 alpha- Cr203 Nanocompisite thin films. Journal of Nanoscience Nanotechnology, 2001;1(4):385-388.

[15] Khairul B., Xianglian, Sainer S., Kouta O., Takashi S., Haruyuki T., Osami A., Naoki I. and Yoshinobu I. Applications of ultrasound to materials chemistry. Indonesian Journal of Physics, 2009;20(1).

[16] Mei Q.S., Lu K. Melting and superheating of crystalline solids: From bulk to nanocrystals. Progress in Materials Science, 2007. 